\title{
SARCOCYSTIS RILEYI EMERGING IN HUNGARY: IS RICE BREAST DISEASE UNDERREPORTED IN THE REGION?
}

\author{
Sándor SZEKERES ${ }^{1 *}$, Alexandra JuHÁsz ${ }^{1}$, Milán $\mathrm{KONDOR}^{2}{ }^{2}$ Nóra TAKÁCS $^{1}$, \\ László SUGÁR ${ }^{3}$ and Sándor HORNOK ${ }^{1}$ \\ ${ }^{1}$ Department of Parasitology and Zoology, University of Veterinary Medicine, \\ István u. 2, H-1078 Budapest, Hungary; ${ }^{2}$ Department of Anatomy and Histology, \\ University of Veterinary Medicine, Budapest, Hungary; \\ ${ }^{3}$ Department of Game Management and Ethology, Faculty of Agricultural and \\ Environmental Sciences, University of Kaposvár, Hungary
}

(Received 17 April 2019; accepted 31 July 2019)

\begin{abstract}
Reports of Sarcocystis rileyi-like protozoa ('rice breast disease') from anseriform birds had been rare in Europe until the last two decades, when S. rileyi was identified in northern Europe and the UK. However, despite the economic losses resulting from $S$. rileyi infection, no recent accounts are available on its presence (which can be suspected) in most parts of central, western, southern and eastern Europe. Between 2014 and 2019, twelve mallards (Anas platyrhynchos) were observed to have rice breast disease in Hungary, and the last one of these 12 cases allowed molecular identification of S. rileyi, as reported here. In addition, $S$. rileyi was molecularly identified in the faeces of one red fox (Vulpes vulpes). The hunting season for mallards in Hungary lasts from mid-August to January, which in Europe coincides with the wintering migration of anseriform birds towards the south. Based on this, as well as bird ringing data, it is reasonable to suppose that the first $S$. rileyi-infected mallards arrived in Hungary from the north. On the other hand, red foxes (Vulpes vulpes), which are final hosts of S. rileyi, are ubiquitous in Hungary, and our molecular finding confirms an already established autochthonous life cycle of $S$. rileyi in the region. Taken together, this is the first evidence for the occurrence of $S$. rileyi in Hungary and its region.
\end{abstract}

Key words: Sarcocystiosis, sarcocystosis, mallard, Anas platyrhynchos, rice breast disease, PCR

Sarcocystis species (Apicomplexa: Sarcocystidae) are cystogenic coccidia with an obligatorily heteroxenous life cycle, involving usually a carnivorous final host and an omnivorous or herbivorous intermediate host. Anseriform birds are intermediate hosts for at least four Sarcocystis species, of which only Sarcocystis rileyi forms macrocysts (Prakas et al., 2014). The presence of such muscle cysts (resembling rice grains) is implied in the generic name of $S$. rileyi infection, i.e. 'rice breast disease'. Waterfowl with 'rice breast disease' (contrary to

*Corresponding author; E-mail: sanyi.szekeres@gmail.com 
this name as a disease and to the 'dramatic' postmortem appearance of the breast muscle) are not much affected. Nevertheless, while the condition resulting from $S$. rileyi infection is not fatal by itself, it may interfere with the energy and protein metabolism of birds (Moorman et al., 1991). In addition, because the largesized cysts can be found in muscles used for locomotion (including the main pectoral muscles powering flight), severe infections may cause muscle loss with resultant weakness, reduced flying capacity or lameness, and such birds may more easily fall victim to predation (Tuggle and Friend, 1999).

Previously, reports on $S$. rileyi-like protozoa in anseriform birds were regarded as rare in Europe (Dubey et al., 2003; Prakas et al., 2014). However, during the past two decades, detailed morphological and molecular analyses confirmed the occurrence of this species in several countries of (primarily) the northern part of Europe, including Poland (Kalisińska et al., 2003), Lithuania (Kutkienè and Sruoga, 2004), Finland (Prakas et al., 2014) and Norway (Gjerde, 2014) (Fig. 1). More recently, raccoon dogs (Nyctereutes procyonoides) and red foxes (Vulpes vulpes) were found to play the final host role in the life cycle of $S$. rileyi in Europe (in Lithuania: Prakas et al., 2015; in Germany: Moré et al., 2016). Surprisingly, despite the potentially high economic losses resulting from $S$. rileyi (i.e., anseriform birds, shot during sport hunting, are not suitable for human consumption), no recently published accounts are available on its presence (which can be suspected) in most parts of central, western, southern, and eastern Europe.

Recently, twelve anseriform birds were observed to harbour $S$. rileyi-like macrocysts in Hungary, and the last one of these cases allowed molecular identification of the species. These new data are summarised in this brief report.

\section{Materials and methods}

Over the past few years, observational records of rice breast disease in Hungary have been provided by official hunters (Table 1). The mallard (Anas platyrhynchos) used for molecular analysis here originated from Ercsi (at the river Danube) in January, 2019. In addition, red foxes (Vulpes vulpes) have been routinely checked by the flotation method for the presence of Sarcocystis sporocysts in their faeces. The fox used as sample source for molecular analysis here was provided by hunters (from Csapod, in February 2019).

Contents of five macroscopic cysts from the breast muscle were used for DNA extraction by the QIAamp DNA Mini Kit (Qiagen Inc., Hilden, Germany) following the manufacturer's instruction (tissue protocol). In addition, the sporocyst-containing supernatant of fox faeces (concentrated by standard flotation) was subjected to five freeze-thaw cycles at room temperature and $-80^{\circ} \mathrm{C}$, then to overnight digestion in tissue lysis buffer and proteinase $\mathrm{K}$ (provided with the QIAamp DNA Mini Kit). Further steps of DNA extraction were the same as for 
the muscle samples. Thus, altogether six DNA extracts were analysed with a PCR method modified from Ho et al. (1996), originally developed to identify cystogenic coccidia on the species level. This PCR amplifies an approx. 350-bp portion of the first part of the 18S rRNA gene of Sarcocystis spp. with the primers COC-1 (5'-AAG TAT AAG CTT TTA TAC GGC T-3') and COC-2 (5'CAC TGC CAC GGT AGT CCA ATA C-3'). Other reaction components and cycling conditions were the same as already reported (Hornok et al., 2015). Purification and sequencing were done at Biomi Ltd. (Gödöllö, Hungary). The sequences [submitted to GenBank, accession numbers: MK510841 (mallard), MN069643 (fox)] were compared to GenBank sequences by the nucleotide BLASTN program (https://blast.ncbi.nlm.nih.gov).

\section{Table 1}

Simplified data of macroscopically suspected and histologically or molecularly verified cases of Sarcocystis rileyi infections from waterfowl (except Germany) during the past two decades in Europe. Since the hosts are migratory birds, only the region is shown for each country (see Fig. 1)

\begin{tabular}{|c|c|c|c|c|}
\hline Year & Country (region) & From mallard & $\begin{array}{c}\text { 18S rRNA } \\
\text { sequence in } \\
\text { GenBank }\end{array}$ & Reference \\
\hline 1999-2000 & Poland (NW) & yes & n. a. & Kalisińska et al., 2003 \\
\hline 1997-2003 & Lithuania (W) & yes & n. a. & $\begin{array}{l}\text { Kutkienė and } \\
\text { Sruoga, } 2004\end{array}$ \\
\hline 2002 & Norway (SN) & no & KJ396583 & Gjerde, 2014 \\
\hline 2010 & Lithuania (C) & yes & HM185742 & Kutkienè et al., 2011 \\
\hline $2011-2013$ & Finland $(\mathrm{S})$ & yes & n. a. & Prakas et al., 2014 \\
\hline 2012 & Germany (NE) & no & KT873746 & Moré et al., 2016 \\
\hline $2015-2018$ & UK (several) & also & $\begin{array}{l}\text { LT992317- } \\
\text { LT992334 }\end{array}$ & Cromie and Ellis, 2019 \\
\hline 2014 & Hungary (SW) ${ }^{1}$ & yes & n. a. & \multirow{4}{*}{ This study } \\
\hline 2017 & Hungary $(\mathrm{W})^{2}$ & yes & n. a. & \\
\hline 2017-2018 & Hungary $(S)^{3}$ & yes ( 9 cases) & n. a. & \\
\hline 2019 & Hungary $(C)^{4}$ & yes & MK510841 & \\
\hline
\end{tabular}

Abbreviations: NW - northwestern, NE - northeastern, SW - southwestern, SN - southern part of northern, C - central, S - southern, W - western, n. a. - not available; Geographic co-ordinates: 1 $46.6409102 \mathrm{~N}, 17.3068933$ E; $2-47.7079835 \mathrm{~N}, 17.2755839$ E; $3-46.0848391-46.4694781 \mathrm{~N}$, 19.4213713-20.1032227 E; $4-47.2482238 \mathrm{~N}, 18.8912626 \mathrm{E}$

\section{Results and Discussion}

Since 2014, 12 cases have been diagnosed in Hungary as rice breast disease, suggestive of $S$. rileyi infection (Table 1, Fig. 1). All of these cases involved mallards (A. platyrhynchos), which had few to many cysts $1 \times 4 \mathrm{~mm}$ in size in their breast muscle (musculus pectoralis major). From all five DNA ex- 
tracts of the last mallard, part of the 18S rRNA gene of a Sarcocystis sp. was successfully amplified. Relevant sequences were identical and showed 100\% $(251 / 251 \mathrm{bp})$ identity only with $S$. rileyi sequences, available in GenBank from Europe (Table 1) and from the USA (GU120092). In addition, the fox faeces was also PCR positive, and the corresponding sequence was $100 \%$ identical with that of $S$. rileyi in the mallard.

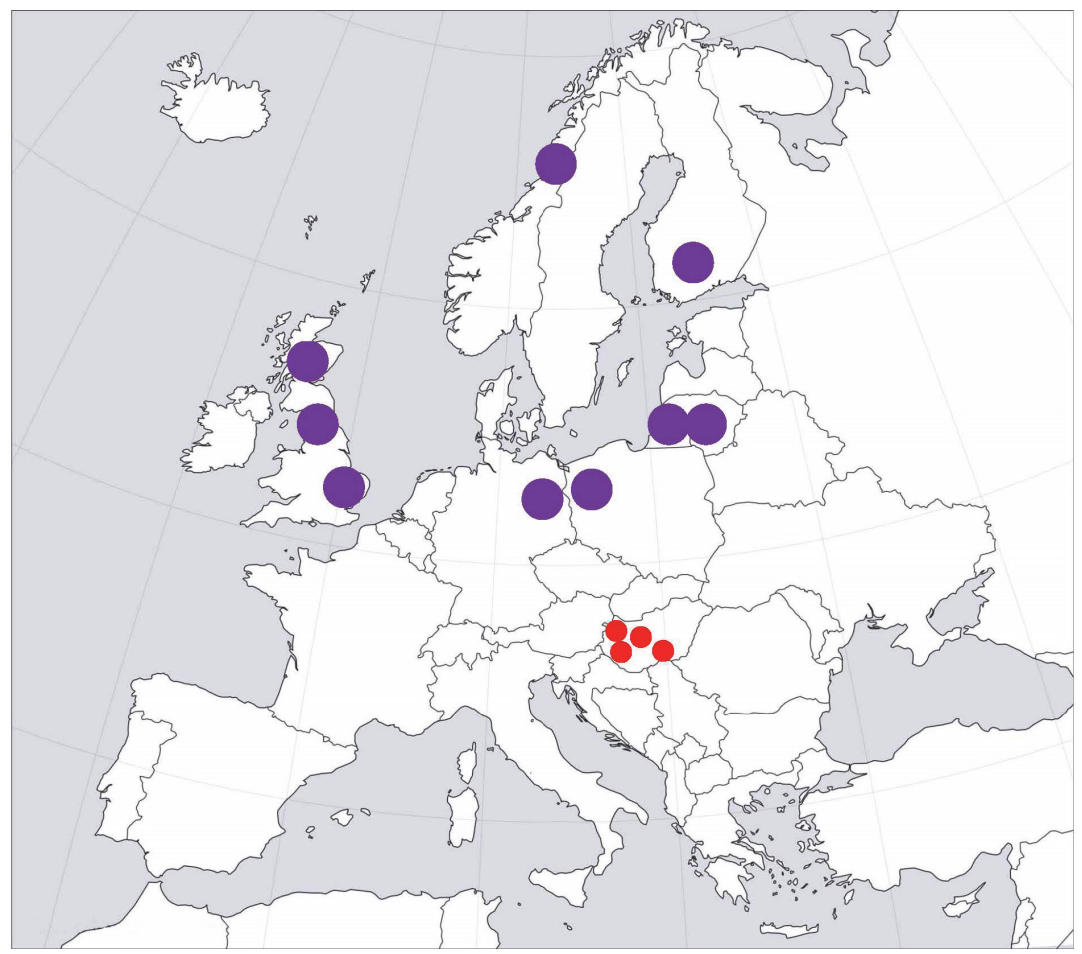

Fig. 1. Map of Europe showing regions according to countries, where Sarcocystis rileyi was reported in the last two decades (purple circles). Four regions of Hungary, where the occurrence of this species is documented here for the first time, are indicated with red dots (according to data in Table 1)

Mallards shot during sport hunting in Hungary are not always plucked and skinned by hunters (Prof. L. Sugár, personal communication), and sometimes not even prior to frying, therefore a significant portion of more recent $S$. rileyi infections in the country may have remained unnoticed and the actual number of cases should inevitably be higher.

The hunting season for mallards in Hungary lasts from mid-August till the end of January, which seasonality is relevant for all of the above 12 cases and coincides with the wintering migration of anseriform birds in Europe towards the south. Hungary is a wintering ground for anseriform birds from the Baltic states 
and northern Europe (Csörgő et al., 2009). In particular, Hungary is the southernmost among those central European countries where mallards (the most important hosts of $S$. rileyi in Europe: Table 1) ringed in Lithuania were recaptured several times between 1930 and 2011 (Švažas et al., 2012). Therefore, it is reasonable to suppose that at least some (of the first) S. rileyi-infected mallards arrived in Hungary from the north, and the emerging tendency of rice breast disease in the country (as shown here and as also reflected by the absence of known cases prior to 2014) is a consequence of bird migration from the direction of the Baltic states towards the south.

On the other hand, red foxes (Vulpes vulpes), which are final hosts of $S . r i-$ leyi (Prakas et al., 2015), are ubiquitous in Hungary. This is suggestive of the establishment and autochthonous occurrence (completion of the life cycle) of S. rileyi in the region, as confirmed by the molecular analysis of fox faeces here. This finding is also relevant in a broader geographical context. Because red foxes occur throughout Europe (Teacher et al., 2011), and anseriform birds such as mallards may arrive even in Mediterranean countries from northern Europe (e.g. Švažas et al., 2012), the current significance of the problem (economic losses attributable to rice breast disease) is almost certainly underestimated in Europe. Taken together, this is the first evidence for the occurrence of $S$. rileyi in Hungary and its region.

\section{Acknowledgements}

Records of previous observations have been provided by official hunters, who observed the relevant law (No. LV/1996, on the protection, management and hunting of game animals) in Hungary. No birds were sacrificed for this study. The mallard (Anas platyrhynchos) used for molecular analysis here was submitted for diagnostic purposes to the Department of Parasitology and Zoology, University of Veterinary Medicine. The molecular work was supported by the 17896-4/2018/FEKUTSTRAT grant of the Hungarian Ministry of Human Capacities. The authors are grateful to hunters from GyörMoson-Sopron, Somogy, Fejér and Csongrád counties for their contributions to the data.

\section{References}

Cromie, R. and Ellis, M. (2019): UK wild fowl Sarcocystis survey: 2015-2018 project report, Available at: http://www.sarcocystissurvey.org.uk/2015-2018-feedback-report/ [accessed February 13, 2019].

Csörgő, T., Karcza, Z., Halmos, G., Gyurácz, J., Magyar, G., Szép, T., Schmidt, A., Bankovics, A. and Schmidt, E. (2009): Hungarian Bird Migration Atlas Kossuth Publishing Zrt., Budapest [in Hungarian, with English summary].

Dubey, J. P., Cawthorn, R. J., Speer, C. A. and Wobeser, G. A. (2003): Redescription of the sarcocysts of Sarcocystis rileyi (Apicomplexa: Sarcocystidae). J. Eukaryot. Microbiol. 50, 476-482.

Gjerde, B. (2014): Molecular characterisation of Sarcocystis rileyi from a common eider (Somateria mollissima) in Norway. Parasitol Res. 113, 3501-3509. 
Ho, M. S., Barr, B. C., Marsh, A. E., Anderson, M. L., Rowe, J. D., Tarantal, A. F., Hendrickx, A. G., Sverlow, K., Dubey, J. P. and Conrad, P. A. (1996): Identification of bovine Neospora parasites by PCR amplification and specific small-subunit rRNA sequence probe hybridization. J. Clin. Microbiol. 34, 1203-1208.

Hornok, S., Mester, A., Takács, N., Baska, F., Majoros, G., Fok, É., Biksi, I., Német, Z., Hornyák, Á., Jánosi, J. and Farkas, R. (2015): Sarcocystis-infection of cattle in Hungary. Parasit. Vectors 8, 69.

Kalisińska, E., Betlejewska, K. M., Schmidt, M., Goździcka-Józefiak, A. and Tomczyk, G. (2003): Protozoal macrocysts in the skeletal muscles of a mallard duck in Poland: the first recorded case. Acta Parasitol. 48, 1-5.

Kutkienè, L. and Sruoga, A. (2004): Sarcocystis spp. in birds of the order Anseriformes. Parasitol. Res. 92, 171-172.

Kutkienè, L., Prakas, P., Sruoga, A. and Butkauskas, D. (2011): Identification of Sarcocystis rileyi from the mallard duck (Anas platyrhynchos) in Europe: cyst morphology and results of DNA analysis. Parasitol. Res. 108, 709-714.

Moorman, T. E., Baldassarre, G. A. and Richard, D. M. (1991): The frequency of Sarcocystis spp. and its effect on winter carcass composition of mottled ducks. J. Wildl. Dis. 27, 491-493.

Moré, G., Maksimov, A., Conraths, F. J. and Schares, G. (2016): Molecular identification of Sarcocystis spp. in foxes (Vulpes vulpes) and raccoon dogs (Nyctereutes procyonoides) from Germany. Vet. Parasitol. 220, 9-14.

Prakas, P., Liaugaudaite, S., Kutkienè, L., Sruoga, A. and Švažas, S. (2015): Molecular identification of Sarcocystis rileyi sporocysts in red foxes (Vulpes vulpes) and raccoon dogs (Nyctereutes procyonoides) in Lithuania. Parasitol. Res. 114, 1671-1676.

Prakas, P., Oksanen, A., Butkauskas, D., Sruoga, A., Kutkienè, L., Švažas, S., Isomursu, M. and Liaugaudaite, S. (2014): Identification and intraspecific genetic diversity of Sarcocystis rileyi from ducks, Anas spp., in Lithuania and Finland. J. Parasitol. 100, 657-661.

Švažas, S., Morkūnas, M., Verhagen, J., Fouchier, R., Morkūnas, J., Mundkur, T., Czajkowski, A., Sruoga, A., Butkauskas, D., Krejaras, R., Jurgelevičius, V., Pridotkas, G., Milius, J., Tubbs, N. and Stanevičius, V. (2012): Surveillance of wild waterbirds for avian influenza viruses in Lithuania. Vet. Med. Zoot. 60, 72-78.

Teacher, A. G., Thomas, J. A. and Barnes, I. (2011): Modern and ancient red fox (Vulpes vulpes) in Europe show an unusual lack of geographical and temporal structuring, and differing responses within the carnivores to historical climatic change. BMC Evol. Biol. 11, 214.

Tuggle, B. N. and Friend, M. (1999): Sarcocystis. In: Cole, R. A. and Friend, M. (eds) Parasites and Parasitic Diseases (Field Manual of Wildlife Diseases). Other Publications in Zoonotics and Wildlife Disease. p. 15.

This is an open-access article distributed under the terms of the Creative Commons Attribution 4.0 International License (https://creativecommons.org/licenses/by/4.0/), which permits unrestricted use, distribution, and reproduction in any medium, provided the original author and source are credited, a link to the CC License is provided, and changes - if any - are indicated. (SID_1) 